\title{
Letters
}

Website: bmj.com

Email: letters@bmj.com

\section{Screening and litigation}

\section{The rate of interval cancers is too high}

EDITOR-The recent wave of litigation in relation to screening for breast and cervical cancer is consistent with the current "compensation culture" but to some extent reflects a failure of both the public and its legal representatives to appreciate the principles and shortcomings of screening programmes.

There is an urgent need to educate women and give them accurate information so that informed decision making can occur and any adverse sequelae are better understood. Despite widespread publicity and vehement lobbying by patients' advocacy groups in the United States, surveys have revealed that women have little knowledge or understanding of the basic screening principles: over three quarters believed that the benefit of screening for breast cancer in women in the 40 to 49 year age group had been proved, and almost $40 \%$ thought screening was effective in women under 40 years of age, though no published data support such a benefit. ${ }^{2}$ Concepts of probability and numeracy may be difficult to convey during a clinical consultation even when the patient seems to understand the issues.

\section{Advice to authors}

We prefer to receive all responses electronically, sent either directly to our website or to the editorial office as email or on a disk. Processing your letter will be delayed unless it arrives in an electronic form.

We are now posting all direct submissions to our website within 24 hours of receipt and our intention is to post all other electronic submissions there as well. All responses will be eligible for publication in the paper journal.

Responses should be under 400 words and relate to articles published in the preceding month. They should include $\leqslant 5$ references, in the Vancouver style, including one to the BMJ article to which they relate. We welcome illustrations.

Please supply each author's current appointment and full address, and a phone or fax number or email address for the corresponding author. We ask authors to declare any competing interest. Please send a stamped addressed envelope if you would like to know whether your letter has been accepted or rejected.

Letters will be edited and may be shortened.

bmj.com

letters@bmj.com
It is perhaps not surprising that the occurrence of interval cancers after a normal screening investigation evokes doubt and confusion, leading women to seek legal and financial recompense. The heterogeneity of breast tumours, with variable mean sojourn times and a range of biological aggressiveness, makes it difficult to estimate the prognostic significance of any delay in diagnosis. However, if a national screening programme is offered to women, certain levels of expectation must be honoured and the screening process rigorously monitored for quality assurance and outcome measures. Data from the NHS breast screening programme indicate that the screening interval is too long: more than $80 \%$ of cancers occurring within the screened population in the third year after a screening mammogram are interval cancers. ${ }^{4}$ Thus almost as many cancers develop between the second and third years as would be expected in an unscreened population. Moreover, interval cancers tend to be more advanced than those detected by screens. False negative rates of up to $40 \%$ have been reported in screening programmes, with retrospective review of mammograms showing a radiological lesion in 20\% of interval cancers and a suspicious abnormality in a further 20\% (S Ciatto, Advanced workshop in breast cancer management, Hong Kong, 1998)

Two view mammography and double reading will help reduce false negative rates, but reducing the time between screens should also help to minimise true interval cancers. These changes will increase the staffing and financial costs of screening but will improve efficacy and in the longer term may avert potential claims of negligence.

J R Benson consultant surgeon

A D Purushotham consultant surgeon

R Warren consultant radiologist

Cambridge Breast Unit, Addenbrooke's Hospital, Cambridge CB2 2QQ

1 Wilson RM. Screening for breast and cervical cancer as a common cause for litigation. BMJ 2000;320:1352-3. (20 May.)

2 Woloshin S, Schwartz LM, Byram SJ, Sox HC, Fischoff B, Welch HG. Women's understanding of the mammographic screening debate. Ann Intern Med 2000;160: 434-40.

3 Schwartz LM, Woloshin S, Black WC, Welch HG. The role of numeracy in understanding the benefit of screening mammography. Ann Intern Med 1997;127:966-72.

4 Woodman CBJ, Threlfall AG, Boggis CRM, Prior P. Is the three year breast screening interval too long? Occurrence of interval cancers in NHS breast screening programme's north western region. $B M J$ 1995:310:224-6.

\section{Measures of validity need to be clear}

EDITOR-Wilson raises important issues in his editorial on screening for breast and cervical cancer, but they are obscured by the incorrect use of terms to describe the validity of tests.'

Specificity of a test measures its ability to correctly identify people without the disease being tested for. A test with $15 \%$ specificity means that only $15 \%$ of people without the disease tested negative and conversely that $85 \%$ without the disease tested positive. If $85 \%$ of women without breast cancer had positive mammograms, mammography would be useless. Wilson probably meant to say that mammography has, at best, only a $15 \%$ positive predictive value-that only $15 \%$ of those with a positive test will actually turn out to have breast cancer. However, the figures he quotes $5 \%$ of women recalled for a further test and 5-6 diagnoses of cancer per thousand women screened) give a positive predictive value for the initial screening mammogram of $10-12 \%$.

The sensitivity of a test measures the proportion of people with the disease that is correctly identified by the test. Mammography is said to have $90 \%$ sensitivity-that is, of every 100 women with undiagnosed breast cancer at the time of the test, 90 will have a positive mammogram and 10 will have a negative one. Wilson goes on to say, however, that in the three year cycle of the NHS screening programme, $40 \%$ of all patients present with symptoms of tumours before the next screening. This means that the overall sensitivity of the programme (as opposed to the mammography) is, at best, $60 \%$. The $40 \%$ of cases not detected by screening are all "false negatives" in terms of the performance of the programme- these patients had negative results on the test but did have or very soon went on to develop the disease.

Whether screening should be continued depends ultimately on its ability to reduce mortality or morbidity in the screened population at an acceptable total cost. Clear measures of the accuracy of the tests and of the risks and benefits that accrue are needed.

Cleone I F Rooney specialist registrar in public health

Kensington, Chelsea and Westminster Health Authority, London W2 6LX cleo.rooney@ha.kcw-ha.nthames.nhs.uk

Laura C Rodrigues reader

Oona M R Campbell senior lecturer

London School of Hygiene and Tropical Medicine, London WC1E 7HT

1 Wilson RM. Screening for breast and cervical cancer as a common cause for litigation. BMI 2000:320:1352-3. (20 May.) 


\section{Some false negatives arise from} negligence

EDITOR-Wilson claims that "negligent false negatives on one hand and an irreducible minimum of screening errors on the other are difficult to reconcile." ${ }^{\prime \prime}$ cannot agree with this statement, at least as far as screening for cervical cancer is concerned.

Several studies have shown that two types of smear give rise to false negative results. ${ }^{23}$ One type contains a small number of abnormal cells $(<200$ per slide) that are hypochromatic, small in size (diameter $<15$ $\mu \mathrm{m})$, and dispersed sparsely across the slide. This type of smear accounts for the "irreducible minimum" of screening errors, and a screener who misreads such a smear does not deserve to be considered negligent. The other type contains numerous hyperchromatic tumour cells ( $>2000$ per slide), which under optimal screening conditions should not be missed. I am frequently asked to review the previous smears of women presenting with invasive cancer who have had a long history of negative smears. Some of these women had five or more "negative" smears in the previous 10 or 12 years. Review of the smears almost always shows that at least one smear contains many obvious tumour cells. Although it is uncomfortable to admit it, there is no satisfactory explanation other than negligence for why these smears were misread.

Women are correct in their perception that cancers arising after a negative smear might have been missed and that delay in diagnosis has prognostic significance. Delay also affects treatment, as preinvasive lesions of the cervix can be treated by laser ablation whereas treatment of invasive cancer usually involves hysterectomy.

Like my colleagues I am deeply concerned at the increasing demand for compensation, but women are justified in assuming that if they present themselves for screening they are entitled to the best possible standard of care. I endorse Wilson's view that screening programmes for both breast and cervical cancer must be given enough resources to ensure that women are offered a service of the highest quality - and so that compensation becomes a thing of the past.

D V Coleman consultant cytopathologist Department of Histopathology and Cytology, Imperial College School of Medicine at Hammersmith Hospital, London W12 0NN d.v.coleman@ic.ac.uk

1 Wilson RM. Screening for breast and cervical cancer as a common cause for litioation. BMJ 2000:320:1352-3. a common

2 Smith PA, Turnbull LS. Small cell and pale dyskariosis. Cytopathology 1997;8:3-8.

3 Baker RW, O'Sullivan JP, Hanley J, Coleman DV. The characteristics of false negative cervical smears-implications for the UK cervical cancer screening programme. J Clin Pathol 1999;52:358-62.

\section{"Blind" rereading of test results provides objectivity}

EDITOR-There are two points to be made about Wilson's editorial. ${ }^{1}$ Firstly, testing in asymptomatic patients differs fundamentally from testing in patients with symptoms. There are no perfect tests, and false negative results of mammography in a patient with symptoms may be "corrected" by clinical or cytological findings, or both, which will not be the case for asymptomatic patients in screening programmes. The clinician interprets the test result in the light of this other information, using bayesian techniques. In asymptomatic patients this is impossible.

Secondly, many if not most false negative smears can be detected on re-examination, but what does this mean from the legal point of view? Does this imply negligence? The Dutch Society for Clinical Pathology recently approved a procedure whereby in a litigation a disputed microscopic slide is not read by a single expert witness but is either reintroduced into normal daily practice in several laboratories where the pathologists are unaware of the outcome or is read by a panel of pathologists who are given a set of similar slides without any knowledge of the outcome or which is the slide under question. This approach circumvents biased reading of slides and gives results that are closer to those of everyday practice.

Raimond W M Giard clinical pathologist and epidemiologist

Department of Clinical Pathology, St Clara Hospital, NL-3078-HT Rotterdam, Netherlands giard@bart.n

\section{Wilson RM. Screening for breast and cervical cancer a a common cause for litigation. BMJ 2000;320:1352-3. (20 May.)}

\section{Author's reply}

EDitor-Benson et al raise the issue of frequency of screening for breast cancer and say that the three year interval of the United Kingdom NHS programme is too long. This seems correct intuitively, but I caution against assumptions made on the basis of data from the early years of this programme. Recently published data show that the breast screening programme as a whole has only recently achieved the cancer detection rate required to achieve the target mortality benefit. ${ }^{1}$ The results of the multicentre, randomised breast screening frequency trial of the United Kingdom Co-ordinating Committee for Cancer Research show that screening every year, rather than every three years, would provide only a marginal benefit in predicted mortality. ${ }^{2}$ However, I am sure that all of us involved in breast screening welcome the recent announcement that breast screening will include two view mammography at every screen and invitation up to the age of 70 , when resources allow.

I am grateful to Rooney et al for their tutorial on statistical nomenclature; they are quite correct in pointing out that I should have used positive predictive value rather than specificity in describing recall for assessment. Whichever measure is used, $85-90 \%$ of women recalled because of a mammographic abnormality do not have breast cancer. Al cancers occurring after a normal screen are indeed false negatives, but in screening parlance the term "false negative" is used, rightly or wrongly, specifically to describe cancers that are detectable on the previous screening test. ${ }^{4}$ The sentiments of my editorial remain the same regardless of nomenclature: we all await mortality data that tell us whether population breast screening is worth while or not.

Coleman correctly reiterates the point that errors range from the obscure to the obvious. However, I take issue with the opinion that all obvious errors are due to negligence. Experts review cases with the benefit of hindsight, as Giard points out, and not in the conditions of the original test. ${ }^{5}$ Errors that seem obvious in retrospect occur even in the best quality screening programmes staffed by highly trained health professionals. To err is human ...

Robin M Wilson consultant radiologist City Hospital, Nottingham NG5 1PB

1 National Health Service Breast Screening Programme. NHS breast screening programme review 1999. Sheffield: NHSBSP, 1999

2 Blamey RW The UKCCCR breast screening frequency trial. Eur J Surg Oncol 1999;25:659-68.

3 The NUS plan: a London: Stationery Office, 2000 . National Health Service Breast Screening Programme. Quality assurance guidelines for radiologists. Sheffield: NHSBSP, 1997.

5 Harvey JA, Fajardo LL, Innis CA. Previous mammograms in patients with impalpable breast carcinoma: retrospective vs blinded interpretation. Am J Roentgenol 1993 161:1167-72.

\section{Reanalysis of Gulf war vaccination data does not contradict findings}

EDIToR-Professors Graham Dunn and Brian Everitt have pointed out to us in a personal communication that a different statistical method would have been more appropriate in our paper on the effects of multiple vaccines on the health of Gulf war veterans. ${ }^{1}$ In that paper we assessed the effect of multiple vaccines received either before or during deployment to the Gulf as two separate exposures. We found that vaccines received before deployment were not associated with most of the outcome measures we looked at, whereas vaccines received during deployment were. We performed the analysis in this way as we were testing a specific a priori hypothesis based on a theory put forward by Rook and Zumla. ${ }^{2}$ However, we did not directly compare these two exposures.

We have performed a series of further analyses in which we entered the two separate exposures (vaccines received before deployment and vaccines received during deployment) in the same model and calculated the differences in regression coefficient for each of the outcome measures, with $95 \%$ confidence intervals (table). None of these differences was significant. The $95 \%$ confidence intervals of four outcome measures-"multisymptom illness" as classified by the Centers for Disease Control and Prevention, fatigue, post-traumatic stress reaction, and "health perception" (a subscale of the SF-36 questionnaire)-are asymmetrical around zero, which is consistent with a difference in effect between multiple vaccines received during deployment and vaccines received before deployment. 
Differences in regression coefficients between vaccines received before and vaccines received during deployment to the Gulf. Positive values indicate greater effect of vaccines received during deployment

\begin{tabular}{lc} 
Outcome measure & $\begin{array}{c}\text { Difference in } \\
\text { regression coefficient } \\
\text { (95\% Cl) }\end{array}$ \\
\hline CDC syndrome* & $0.18(-0.02$ to 0.39$)$ \\
\hline Fatigue & $0.17(-0.03$ to 0.37$)$ \\
\hline General health questionnaire & $0.02(-0.18$ to 0.22$)$ \\
\hline Post-traumatic stress reaction & $0.29(-0.01$ to 0.59$)$ \\
\hline SF-36† physical function & $0.65(-0.58$ to 1.88$)$ \\
\hline SF-36† health perception & $1.56(-0.70$ to 3.82$)$ \\
\hline
\end{tabular}

${ }^{*}$ Multisymptom illness as classified by the Centers for Disease Control and Prevention.

†Short form 36 , a health status questionnaire.

Our paper showed large differences in the effects of multiple vaccines on health according to whether they were received before or during deployment. The results of this alternative method indicate that there may be no difference. However, these findings do not necessarily contradict those reported in our paper: an effect might be detected in the revised analysis only with a larger sample. It is reasonable to conclude that multiple vaccines received during deployment have a greater effect than those received before deployment, but we have not shown that multiple vaccines received before deployment are without risk. We say again that these are preliminary findings that require replication and also that they have no bearing on public vaccination programmes. Our results still indicate, as did our earlier paper," that there is a link between multiple vaccines and illness in veterans of the Gulf war.

Matthew Hotopf senior lecturer

Department of Psychological Medicine, Guy's,

King's College, and St Thomas's School of

Medicine, King's College London, London

SE5 8AZ

spjumhh@iop.kcl.ac.uk

1 Hotopf M, David A, Hull L, Ismail K, Unwin C, Wessely S. Role of vaccinations as risk factors for ill health in veterans of the Gulf war: cross sectional study. BMJ 2000; 320:1363-7. (20 May)

2 Rook GAW, Zumla A. Gulf war syndrome: is it due to a systemic shift in cytokine balance towards a Th2 profile? Lancet 1997;349:1831-3.

3 Unwin C, Blatchley N, Coker W, Ferry S, Hotopf M, Hull L, et al. Health of UK servicemen who served in the Persian Gulf war. Lancet 1999;353:169-78.

\section{Clinical judgment is important for individual patients}

EDitoR-Williams et al comment on the provision of private operations and make several sweeping statements. ${ }^{1}$ They question the efficacy of myringotomy and grommet insertion, and allege that some health authorities are refusing to fund them. The British Association of OtolaryngologistsHead and Neck Surgeons is not aware of any such purchasing decisions currently in place with regard to grommet insertion. The effectiveness of grommet insertion and the long term effects of surgery compared with no surgery are the subject of a multicentre trial by the Medical Research Council, which is nearing completion. The main decision does not concern effectiveness of treatment but rather which children have persistent problems. To paraphrase Professor Mark Haggard, the MRC's trial coordinator: "Deciding when to intervene is difficult because you only know when it's too late that you should have intervened." 2

The article by Williams et al helps to show that making decisions about populations of people is one thing but to apply those decisions rationally to individual patients is quite another. This is where clinical judgment comes in.

Their further comment that the Commission for Health Improvement has to ensure that treatments are evidence based but that its remit doesn't apply to the private sector may be irrelevant. Patients often come to the private sector because they do not want to be treated according to a set of fixed rules (as in drug prescribing) that assume one size fits all. The NHS has always had to make harsh choices, but these include criteria based on funding and access, which do not necessarily apply in the commercial world of health care.

Antony A Narula chairman, Clinical Practice Advisory Group

British Association of Otolaryngologists-Head and Neck Surgeons, Roval College of Surgeons of England, London WC2A 3PN orl@bao-hns.demon.co.uk

1 Williams B, Whatmough P, McGill J, Rushton L. Private funding of elective hospital treatment in England and Wales. BMJ 2000;320:904-5. (1 April.)

2 Derrington $\mathrm{A}$. Why hearing today may be gone tomorrow. Financial Times 2000; Apr 1-2 (weekend suppl): II.

\section{Screening for Down's syndrome}

\section{Biochemical screening offers advantages}

Editor-We were interested in the findings of Howe et al on screening for Down's syndrome in Southampton and their suggestion that the benefits of mid-trimester serum screening have been overrated. ${ }^{1}$ The Women's Centre at the John Radcliffe Hospital in Oxford has a similar population in terms of the number of deliveries and the percentage of women having prenatal karyotyping $(7 \%)$ and has a similar screening policy for Down's syndrome: amniocentesis offered to women aged $\geqslant 35$ at expected date of delivery; no serum or nuchal translucency screening through the NHS (some women organise this privately). The population at the Women's
Centre has a higher distribution in maternal age $(16 \%$ aged $\geqslant 35$, compared with $10 \%$ in Southampton).

We performed a similar analysis on 78 cases of Down's syndrome in 1993-8 in which the fetus was alive at the time of scan (table). Forty three $(55 \%)$ cases were diagnosed prenatally before 24 weeks' gestation; in mothers aged under 35 years this rate was $41 \%$. Of the 35 cases not prenatally diagnosed before 24 weeks' gestation, eight were in babies born to women aged $\geqslant 35$ years (eligible for amniocentesis). The increase in prenatal detection in Oxford in 1993-8 was mostly due to suspicion at the anomaly scan. However, the detection rate in Oxford is lower than that reported in Southampton, despite the higher maternal age in Oxford.

We agree that there are advantages to using the anomaly scan as a screening tool for Down's syndrome-it is more economical, there is a single intervention, and other chromosomal abnormalities are more readily detected-but there are also disadvantages. For example, most women are not aware that the anomaly scan may lead to the detection of Down's syndrome and a relatively late diagnosis. Biochemical screening would have some advantages: earlier diagnosis, more informed consent (with appropriate pretest counselling), and a higher detection rate for a lower false positive rate (and hence fewer normal babies lost through miscarriage). We agree with Howe et al that it is important to obtain evidence of the effectiveness of new screening methods ${ }^{2}$ and to compare them with current practice before their widespread introduction.

P A Boyd clinical geneticist for prenatal diagnosis trishaboyd@hotmail.com

M Jefferies maternity information officer P F Chamberlain consultant obstetrician Women's Centre, Oxford Radcliffe Hospitals NHS Trust, Oxford OX3 9DU

A J M Crocker cytogeneticist

Oxford Genetics Laboratories, Oxford Radcliffe Hospitals NHS Trust, Oxford OX3 7DA

1 Howe DT, Gornall R, Wellesley D, Boyle T, Barber J. Six year survey of screening for Down's syndrome by materna year survey of screening for Down's syndrome by maternal
age and mid-trimester ultrasound scans. BMJ 2000; age and mid-trimester

2 Wald NJ, Watt HC, Hackshaw AK. Integrated screening for Down's syndrome based on tests performed during the first and second trimesters. N Engl J Med 1999;341:461-7.

\section{Serum screening shows a clear benefit} across age groups

EDITOR-Howe et al call for evidence of the effectiveness of new screening programmes for Down's syndrome in properly conducted

\begin{tabular}{|c|c|c|c|c|c|c|}
\hline \multicolumn{7}{|c|}{ Diagnosis of Down's syndrome according to stage of gestation } \\
\hline \multirow[b]{3}{*}{ Year } & \multirow[b]{3}{*}{ Total no } & \multicolumn{4}{|c|}{ Diagnosed prenatally before 24 weeks' gestation } & \multirow[b]{3}{*}{$\begin{array}{l}\text { Diagnosed postnatally or after } \\
24 \text { weeks' gestation }\end{array}$} \\
\hline & & \multirow[b]{2}{*}{ Total (\%) } & \multicolumn{3}{|c|}{ Primary reason for karyotyping } & \\
\hline & & & Maternal age & $\begin{array}{l}\text { Serum } \\
\text { screen }\end{array}$ & $\begin{array}{l}\text { Suspicious } \\
\text { scan }\end{array}$ & \\
\hline 1993 & 5 & $2(40)$ & 2 & 0 & 0 & 3 \\
\hline 1994 & 15 & $7(47)$ & 4 & 1 & 2 & 8 \\
\hline 1995 & 14 & $8(57)$ & 3 & 1 & 4 & 6 \\
\hline 1996 & 11 & $7(64)$ & 3 & 2 & 2 & 4 \\
\hline 1997 & 12 & $8(67)$ & 2 & 2 & 4 & 4 \\
\hline 1998 & 21 & $11(52)$ & 1 & 3 & 7 & 10 \\
\hline Total & 78 & $43(55)$ & 15 & 9 & 19 & 35 \\
\hline
\end{tabular}


controlled trials that state the age structure of the population studied. ${ }^{1}$ The population of pregnant women in this area, Milton Keynes, is similar in age to their population, but our results-though not part of a randomised controlled trial-are different.

In Howe et al's Southampton study 10\% of the women were aged 35 or older; the proportion here in the six years 1994-9 was $12 \%$. Howe et al report that the rate of Down's syndrome in women in this age group is usually given as $20-30 \%$. In the 38 cases in the screened population in Milton Keynes, $14(37 \%)$ of the mothers were over the age of 35 . This contrasts with $61 \%$ in this age group in Southampton.

From 1991 to 1993 our policy for detection of Down's syndrome was similar to that in Southampton: amniocentesis in women aged $\geqslant 35$ and in women with ultrasound markers for chromosomal abnormalities detected on routine anomaly scans at $18-20$ weeks or incidental scans performed for clinical reasons. Half of the 20 cases occurring in these three years were detected. In 1994 serum screening using $\alpha$ fetoprotein and free $B$ human chorionic gonadotropin was introduced. In the 38 cases a positive screen (risk $>1: 250)$ occurred in $33(87 \%)$. Two further cases were detected from the anomaly scan, bringing the total to 35 (92\%). The detection rate of serum screening plus routine ultrasound scanning was 22 out of $24(92 \%)$ in women aged $\geqslant 35$.

Howe et al say that serum screening may be more beneficial in a population younger than theirs. As we have shown in a population with a similar age structure to theirs, using serum screening rather than maternal age as the main indication for amniocentesis has a clear benefit. Furthermore, we found that although maternal age was part of the formula for calculating risk status, half the women aged over 40 were able to avoid amniocentesis.

G S McCune consultant obstetrician

A S Stock consultant obstetrician

A Foakes prenatal screening co-ordinator

Milton Keynes General NHS Trust, Milton Keynes MK6 5LD

1 Howe DT, Gornall R, Wellesley D, Boyle T, Barber J. Six year survey of screening for Down's syndrome by maternal age and mid-trimester ultrasound scans. BMJ 2000 320:606-10. (4 March.)

\section{Data do not support study's claim}

EDITOR-Howe et al say that screening for Down's syndrome by maternal age and mid-trimester ultrasound scanning may perform as well as screening using serum markers and age. ${ }^{1}$ This conclusion is wrong, as they report a detection rate of $68 \%$ for a false positive rate of $6.6 \%$ and a detection time as late as 24 weeks' gestation. This is clearly inferior to prospective serum screening, the cumulative results of which show a similar detection rate with a false positive rate of only $4.5 \%{ }^{2}$-and confirmatory amniocentesis can be performed before 18 weeks' gestation.

In a recent serum screening programme for Down's syndrome in 17023 low risk pregnancies in one county in Denmark the detection rate was $68 \%$ and the false positive rate $4.1 \%{ }^{3}$ Further scanning reduced that figure to $3.0 \%$, corresponding to 30 amniocenteses per case of Down's syndrome, compared with 105 amniocenteses per case in the $\geqslant 35$ age group in the same county.

Screening in the Southampton study was based on maternal age ( $\geqslant 35$ years), an anomaly scan at 19 weeks' gestation, and apparently also $\alpha$ fetoprotein screening for spina bifida. Serum $\alpha$ fetoprotein results will certainly improve the effectiveness of the anomaly scan for detecting Down's syndrome. Howe et al said the age structure of the population could be estimated from laboratory records of $\alpha$ fetoprotein screening; it is difficult to understand this as most women aged $\geqslant 35$ have amniocentesis without any prior $\alpha$ fetoprotein determination. With only $10 \%$ of pregnant women above 35 years of age, how is it possible that two thirds of cases of Down's syndrome are found in this group? These figures raise a suspicion of selection bias, as only a quarter of cases are expected in this age group, according to UK data. Combining the prospective data from a serum screening programme in Cambridge ${ }^{4}$ with the age distribution from Southampton ${ }^{1}$ gives a detection rate of $84 \%$ for a false positive rate of $<5 \%$. Furthermore, a recent similar study in Scandinavia on ultrasound anomaly scanning at 18-20 weeks' gestation found a much lower detection rate $(6.3 \%)$ among women aged under 35 years. ${ }^{5}$

The Southampton data therefore do not support the claim that it is necessary to conduct a controlled comparison of screening by maternal age plus anomaly scan versus conventional serum screening in the second trimester. On the contrary, the effectiveness of serum screening is highly evidence based, and resources would be better spent on controlled trials of serum and ultrasound screening in the first trimester.

Bent Norgaard-Pedersen professor

Department of Clinical Biochemistry, Statens Serum Institut, DK-2300 Copenhagen, Denmark bnp@ssi.dk

\section{Howe DT, Gornall R, Wellesley D, Boyle T, Barber J. Six year survey of screening for Down's syndrome by matern age and mid-trimester ultrasound scans. BMJ 2000; 320:606-10. (4 March.) \\ 2 Cuckle H. Established markers in second trimester mater- nal serum screening. Early Hum Dev 1996;47(suppl) $27-95$ \\ 3 Christiansen M, Petersen PL, Permin M, Larsen LA, Nørgaard-Pedersen B. Maternal serum screening for con- gental 1999:161:6928-34. \\ 4 Goodburn SF, Yates JRW, Raggatt PR, Carr C, Ferguson- Smith ME, Kershaw AJ, et al. Second trimester materna serum screening using alpha-fetoprotein, human chori- onic gonadotrophin, and unconjugated oestriol: experi- ence of a regional programme. Prenatal Diagnosis 1994;14:391-402. \\ 5 Jørgensen FS, Valentin L, Salvesen KA, Jørgensen C, Jensen FR, Bang J, et al. MULTISCAN-a Scandinavia multicenter second trimester obstetric ultrasound an serum screening study. Acta Obstet Gynecol Scan 1999;78:501-10.}

\section{Statistical modelling is best tool for} formulating screening policy

Editor-Howe et al are incorrect in saying that the detection rate of Down's syndrome in Southampton using maternal age and ultrasound anomaly scanning in the second trimester is considerably higher than that found elsewhere with serum screening. ${ }^{1}$

Twenty one large prospective intervention studies of multi-marker, second trimester serum screening have been published. ${ }^{2}$ In total 353000 women were screened, and there were 514 cases of Down's syndrome. Protocols varied: 13 studies used three markers, eight used two; 16 screened everyone, five screened only young women; there were 13 different cut-off ages. Overall there was a $67 \%$ detection rate and a false positive rate of $4.5 \%$, compared with $68 \%$ and $6.6 \%$, respectively, in Southampton. Intervention studies are positively biased because of the detection of non-viable true positives. Assuming 25\% non-viability, the rates become $60 \%$ in the combined studies and $61 \%$ in Southampton (adjusted rate $=0.75 \mathrm{D} /(0.75 \mathrm{D}+\mathrm{U})$, where $\mathrm{D}=$ diagnosed cases and $\mathrm{U}=$ undiagnosed cases).

Statistical modelling, a reliable tool in formulating policy on screening for Down's syndrome, shows that screening by maternal age alone is ineffective: in England and Wales in 1993-7 only 30\% of affected pregnancies were predicted in the oldest $5 \%$ of women. Statistical modelling also shows that the results of the 21 prospective studies of serum screening are in line with predictions. ${ }^{2}$

Models of anomaly scanning in the second trimester have not been sufficiently validated, but modelling is possible for nuchal translucency scanning in the first trimester. This predicts a $73 \%$ detection rate for a $5 \%$ false positive rate. The rate of $78 \%$ for $8 \%$ reported in the Fetal Medicine Foundation study is, after allowance for viability bias, in line with predictions. ${ }^{3}$ Combining nuchal translucency screening with first trimester serum markers predicts a detection rate of $88 \%$ for a false positive rate of $5 \%$

The Southampton results are good, but studies on anomaly scanning are not always reproducible. Until these results are confirmed by other studies, planners would best be guided by modelling. This favours serum screening, ideally in the first trimester, combined with nuchal translucency scanning.

Howard Cuckle professor of reproductive epidemiology University of Leeds, Leeds LS2 9NZ

h.s.cuckle@leeds.ac.uk

1 Howe DT, Gornall R, Wellesley D, Boyle T, Barber J. Six year survey of screening for Down's syndrome by maternat age and mid-trimester ultrasound scans. BMJ 2000; 320:606-10. (4 March)

2 Cuckle $\mathrm{H}$, Murray J Screening for neurological disorders In: Levene MI, Whittle MJ, Chervenak FA, Punt J, Bennet MJ, eds. Fetal and neonatal neurology and neurosurgery. London: Churchill Livingstone (in press).

3 Snijders RJM, Noble P, Sebire N, Souka A, Nicolaides KH UK multicentre project on assessment of risk of trisomy 21 by maternal age and fetal nuchal-translucency thickness 10-14 weeks of gestation. Lancet 1998;352:343-6.

4 Cuckle HS, van Lith JMM. Appropriate biochemical parameters in first trimester screening for Down' syndrome. Prenat Diagn 1999;19:505-12.

Serum screening programmes are effective and safe

Editor-Howe et al incorrectly conclude that the value of serum screening for Down's syndrome in the second trimester is lower than supposed. ${ }^{1}$ They present no direct evidence to show this-and could not do so, as serum screening was not offered to the 
population in the Southampton study. Their conclusion rests on comparing a large screening effect of maternal age in their data with historical reports of serum screening. The comparison is distorted, however, by an inexplicably high number of affected pregnancies in women aged $\geqslant 35$ : 36 out of 53 cases of Down's syndrome (68\%; $95 \%$ confidence interval $54 \%$ to $80 \%$ ) occurred in women in this age group, a proportion so high that it suggests methodological error. In England and Wales in 1996-7 only 50\% of cases of Down's syndrome occurred in women aged $\geqslant 35,{ }^{2}$ even though the proportion of women in this age group $(13.1 \%)^{3}$ was greater than in Southampton $(10.5 \%)$. One would therefore expect less than $50 \%$ of Down's syndrome in this age group in Southampton, not more. No explanation for the anomalous result is given.

The value of screening by maternal age and ultrasound cannot be adequately determined from the paper as it mainly depends on the high proportion of affected pregnancies in women aged $\geqslant 35$. The reported detection rate of $17 \%(9 / 53)$ for anomaly scanning is not interpretable because no corresponding false positive rate is given. Also, because women aged $\geqslant 35$ were offered amniocentesis at 16 weeks' gestation, it is not known how many of these women would have had a positive scan at 19 weeks had their pregnancies not been terminated after their amniocentesis.

Serum screening includes maternal age and cannot therefore have a worse performance than screening by maternal age alone; indeed, individually each serum marker, except $\alpha$ fetoprotein, is better than maternal age in distinguishing affected from unaffected pregnancies. ${ }^{45}$

Howe et al say that there has never been a controlled trial of serum screening. There is no need for one because the best evidence is from a direct comparison of screening strategies in the same women, evidence that is available from serum screening programmes. For example, the results over 10 years from the screening programme at Barts $(87380$ women, including 139 with affected pregnancies) show that serum screening, using the triple or quadruple test, identified $45 \%$ more Down's syndrome cases than would have occurred had screening been based on maternal age alone (94 cases (rate of detection 68\%) v $65(47 \%)$ ), with only half the number of amniocenteses (5211 (rate 6\%) v 10353 (12\%)). This shows unequivocally that serum screening is a more effective and safer strategy.

NJ Wald professor

A K Hackshaw lecturer

W Huttly antenatal screening manager

Department of Environmental and Preventive

Medicine, Wolfson Institute of Preventive Medicine, St Bartholomew's and the Royal London School of Medicine and Dentistry, London EC1M 6BQ

1 Howe DT, Gornall R, Wellesley D, Boyle T, Barber J. Six year survey of screening for Down's syndrome by maternal age and mid-trimester ultrasound scans. BMJ 2000; 320:606-10. (4 March.)

2 Mutton D, Ide RG, Alberman E. Trends in prenatal screening for and diagnosis of Down's syndrome: England and Wales 1989-97. BMJ 1998,317:922-3.
3 Office for National Statistics. Birth statistics. London HMSO, 1996, 1997. (Series FM1, Nos 25, 26.

4 Wald NJ, Densem JW, Smith D, Klee GG. Four-marke serum screening for Down's syndrome. Prenat Diagn 1994;14:707-16

5 Wald NJ, Densem JW, Muttukrishna S, Knight PG. Prenatal screening for Down's syndrome using inhibin-A as serum marker. Prenat Diagn 1996:16:143-53. [Published correction appears in Prenat Diagn 1997;17:285-90.]

\section{A large independent trial would be useful}

EDITOR-Many years ago, prenatal screening for Down's syndrome was available only by amniocentesis, which was performed if a pregnant women was over a certain age. That changed in 1988 when Wald et al published the results of their triple screen method. ${ }^{1}$ Since then we have seen the proposal of increasingly Byzantine screening protocols to wring out the last possible percentage of detection. Recently (straining ethics to the limit) it has even been suggested that screening by ultrasonography and biochemical testing should be carried out in the first trimester, the results being withheld to be combined later with second trimester results ${ }^{2}$-all this despite a lack of evidence that adding further tests provides any significant increase in the rate of detection. ${ }^{3}$ It is therefore refreshing that Howe et al have challenged the orthodoxy and shown that detection rates similar to those achievable by serum screening can be achieved by ultrasound screening alone. ${ }^{4}$

Howe et al's report indicates that it would be ethical to carry out a randomised trial comparing ultrasonography with serum screening, as ultrasound screening alone would not disadvantage any patient. It would be essential to examine a very large number of pregnancies (at least 250000 pregnancies per group), with $50 \%$ of patients in each participating site receiving the results of their serum screen and the other half receiving ultrasonography results (but with serum samples collected) in order that true differences in detection rates could be identified. A trial of that size is needed because the confidence intervals for detection rates are so large. ${ }^{3}$ Furthermore, anyone organising such a trial must be beyond reproach-for example, having no vested interest by virtue of patent ownership in proving that either form of screening should prevail. ${ }^{4}$ Such a trial has the potential to save the NHS large sums of money; a proper comparison of the efficiency of the two methods should be carried out soon.

Tim Reynolds professor of chemical pathology Queen's Hospital, Burton upon Trent DE13 0RB Tim.Reynolds@Queens.Burtonh-tr.wmids.nhs.uk

1 Wald NJ, Cuckle HS, Densem JW, Nanchalal K, Royston P, Chard T, et al. Maternal serum screening for Down's
syndrome in early pregnancy. BMJ 1988;297:883-7. syndrome in early pregnancy. BMJ 1988;297:883-7.
Wald NJ, Watt HC, Hackshaw AK. Integrated screening for 2 Wald NJ, Watt HC, Hackshaw AK. Integrated screening for Down's syndrome based on tests performed during the first and second trimesters. N Engl J Med 1999;341:461-7. 3 Reynolds TM. Down's syndrome screening: a controversial test, with more controversy to come! J Clin Path (in press) 4 Howe DT, Gornall R, Wellesley D, Boyle T, Barber J. Six year survey of screening for Down's syndrome by materna age and mid-trimester ultrasound scans. BMJ 2000; 320:606-10. (4 March.)

\section{Authors' reply}

EDIToR-Boyd et al, using maternal age as their primary screening determinant, achieved detection rates for Down's syndrome that were, like ours, higher than predicted and within the range reported for serum screening in demonstration projects. McCune et al added further data on serum screening but did not answer our questions because, as with previous studies, there was no control group with a similar age distribution.

Norgaard-Pedersen misunderstands the use of $\alpha$ fetoprotein testing in Southampton. We do not use it to modify the mother's age related risk of Down's, and we do not routinely measure liquor $\alpha$ fetoprotein in women having amniocentesis-it is offered to all women, and we are not aware of any difference in take up according to age. Norgaard-Pedersen says that our false positive rate $(6.6 \%)$ is higher than it would be with serum screening. He compares our amniocentesis rate with accumulated data from several demonstration projects. Without knowing the age structure of the populations in these studies one can not make such a comparison. He claims that our method results in later diagnosis. The reverse is the case: most women in Southampton have their amniocentesis from 16 weeks' gestation, without the delay imposed by waiting for serum screen results. Women who arrange a private serum screen do not usually have their amniocentesis until a week later. We took 24 weeks' gestation as our cut-off point because of the difficulty of performing termination after this time; as we said in our paper, the latest detection was at 20 weeks' gestation. Some cases will also be detected at this later stage where serum screening and also routine ultrasound are used.

Cuckle has misrepresented what we concluded. We did not state that using maternal age and ultrasonography was better than serum screening but that our detection rate was much higher than the rate that demonstration projects of serum screening predicted for age screening. Our results are important precisely because they are so different from those predicted by the statistical modelling he advocates: an antenatal detection rate of $68 \%$ rather than the $30 \%$ predicted by such modelling. We are not advocating screening by ultrasonography alone, but we found that routine mid-pregnancy scanning was one of the factors that led to the discrepancy between the predictions and our results.

Wald et al criticise our results because they do not fit their predictions for the proportion of affected pregnancies occurring in women aged $\geqslant 35$. Three explanations for this discrepancy are that our results are a statistical fluke, that our data are wrong, and that statistical modelling does not accurately predict what happens in practice. We know from the Wessex database of congenital anomalies that the age distribution of mothers with affected pregnancies is similar in all the health districts in the Wessex region, suggesting that our results are not atypical (unpub- 
lished data). We do not believe that we have failed to identify large numbers of affected babies born to women under 35 , the only explanation for an error in our data: all suspected cases in Southampton are tested in a single cytogenetics laboratory, and the Wessex database receives data both from the laboratory and from paediatricians to ensure that the information is as complete as possible.

This leaves the third possibility, that the modelling does not predict what happens in practice. The great strength of our study is that it describes what was actually achieved in detecting affected pregnancies in the entire local population over an extended period. There are considerable cost implications in selecting the best screening policy for Down's syndrome. We leave it to others, particularly those involved in healthcare planning, to judge whether the statistical modelling that Cuckle and Wald et al advocate can be relied on as a "reliable tool in formulating policy."

David Howe consultant in fetomaternal medicine Wessex Maternal and Fetal Medicine Unit, Princess Anne Hospital, Southampton SO16 5YA dth@soton.ac.uk

Diana Wellesley associate specialist in clinical genetics Wessex Clinical Genetics Service, Princess Anne Hospital

Tracy Boyle section head, prenatal diagnostics John Barber deputy director, cytogenetics laborator Wessex Regional Genetics Laboratory, Salisbury District Hospital, Salisbury SP2 8BJ

\section{Amoxicillin for otitis media in general practice}

\section{Parental expectations must be dealt with}

EDITOR-The study by Damoiseaux et al adds greatly to the evidence that antibiotics are of limited use in children of all ages with uncomplicated otitis media. ${ }^{1}$ In consultations in general practice, however, the decision to prescribe is greatly influenced by considerations arising from the doctorpatient relationship. ${ }^{2}$ Often doctors find it difficult to convince worried parents that watchful waiting is acceptable treatment for their child.

Many parents see watchful waiting as no treatment and are disappointed by the outcome of the consultation. Sleepless nights, the effort spent in attending the surgery, previous experience, and views of relatives may all increase the expectation of treatment. The challenge in general practice is to present the evidence in such a way that parents feel empowered at the end of the consultation and more able to cope with the problems their children experience, rather than disempowered when their expectations are not met. General practitioners are faced with this dilemma every day. In their qualitative study of the reasons why antibiotics were prescribed for sore throats, Butler et al found that patients' expectations were seldom explicit, and many were not met. ${ }^{2} \mathrm{~A}$ third of patients clearly expected a prescription for antibiotics, but satisfaction was not necessarily related to receiving antibiotics, many patients instead seeking reassurance, further information, and pain relief. Educational campaigns may help to reassure parents, ${ }^{3}$ and general practitioners' confidence may be improved with the increasing use of decision aids in the surgery. These aids stimulate patients to be more active in decision making without increasing their anxiety, but unfortunately have little effect on satisfaction. ${ }^{4}$

Repeating the evidence for lack of effectiveness is unlikely to change doctors prescribing. Instead, Butler et al concluded that information should be presented in terms of the risk to individual patients, emphasising the positive aspects of no being treated with an antibiotic and their general lack of efficacy. Further research is needed to help us as doctors to understand our patients' perspectives and improve our ability to be health educators rather than just healthcare providers.

Andrew Thornett clinical research fellow Department of Psychiatry, University of Southampton, Royal South Hants Hospital, Southampton SO14 0Y

Geanador@usa.net

1 Damoiseaux RAMJ, van Balen FAM, Hoes AW, Verheij TJM, de Melker RA. Primary care based randomised, double blind trial of amoxicillin versus placebo for acute otiti media in children aged under 2 years. BMJ 2000; 320:350-4. (5 February)

2 Butler CC, Rollnick S, Pill R, Maggs-Rapport F, Stott N. Understanding the culture of prescribing: qualitative study of general practitioners' and patients' perceptions of antibiotics for sore throats. BMJ 1998;317:637-42.

3 Belongia EA, Schwartz B. Strategies for promoting judicious use of antibiotics by doctors and patients. $B M$ 1998;317:668-71

O'Connor AM, Rostom A, Fiset V, Tetroe J, Entwistle V, Llewellyn-Thomas H, et al. Decision aids for patients facing health treatment or screening decisions: systematic review. $B M J$ 1999;319:731-4

\section{Time to stop misuse of antibiotics}

EDITOR-Nearly 20 years after the first modern randomised clinical trial by van Buchem et $\mathrm{al}^{1}{ }^{1}$ Damoiseaux et al finally dispel the myth of mandatory antibiotic treatment for acute otitis media. ${ }^{2}$ They show that even in children at high risk (aged under 2 years) antibiotic treatment is ineffective, thereby extending the findings of van Buchem et al to all age groups.

Though the results of van Buchem et al were confirmed by Danish and Swedish clinical trials in 1981 and 1986, two misleading trials published in 1991 under the influence of antibiotic manufacturers perpetuated the myth of the effectiveness of antibiotics. ${ }^{3}$ Consequently, in the United States annual antibiotic consumption for otitis media has increased dramatically to over 30 million prescriptions. Antibiotic misuse in otitis media has contributed greatly to the current epidemic of multidrug resistant Streptococcus pneumoniae.

American children during the first 2 years of life spend an astounding 90 days taking antibiotics. ${ }^{4}$ This may be causally related to the current increase in chronic respiratory diseases such as wheezing and asthma in young children. Last year a research group from Boston reported that $32 \%$ of such children wheeze, $26 \%$ use bronchodilators, and 12\% have asthma before the age of 5 years (A L Fuhlbrigge et al, American Lung Association/American Thoracic Society international conference, San Diego, April 1999).

Nine years after the two misleading 1991 articles (one was the subject of an extensive fraud investigation by the United States government) there is finally an unassailable randomised clinical trial that supports the watchful waiting approach of withholding antibiotics for acute otitis media, even for young infants. Children under the age of 2 years, who are considered to be at risk of a poor outcome, were the favoured target for antibiotic advocates. These leading experts argued, without scientific evidence, that such children should always be treated with antibiotics for at least 10 days and often with multiple courses of wide spectrum newer antibiotics for extended periods, up to months of antibiotic prophylaxis.

Considering the alarming rise in the prevalence of drug resistant bacterial pathogens and chronic lung diseases among children, doctors must lead the effort to curb misuse of antibiotics. It is time to switch to effective pain management such as local analgesia (20\% benzocaine ear drops) and systemic pain relief (paracetamol) as the first line treatment of acute otitis media and to stop dispensing ineffective drugs with proved serious adverse effects on both children and the community at large.

Erdem I Cantekin professor of otolaryngology University of Pittsburgh School of Medicine, Children's Hospital of Pittsburgh, 125 De Soto Street, Pittsburgh, PA 15213, USA

1 Damoiseaux RAMJ, van Balen FAM, Hoes AW, Verheij TJM, de Melker RA. Primary care based randomised, double blind trial of amoxicillin versus placebo for acute otitis media in children aged under 2 years $B M I$ 2000; media in children aged

2 Van Buchem FL Dunk JHM, van't Hof MA. Therapy of acute o double blind study in children. Lancet 1981;ii:883-7.

3 Cantekin EI. Aggressive and ineffective therapy for otitis Cantekin EI. Aggressive and ineffective the

media. Otorhinolaryngol Nova 1998;8:136-47. Paradise JL, Rockette He, Colborn DK, Bernard BS, Smith
CG, Kurs-Lasky M, Janosky JE. Otitis media in 2253 Pittsburgh-area infants: prevalence and risk factors during the first two years of life. Pediatrics 1997;99:318-33.

\section{A grandparent's view}

EDITOR-As the grandparent of a 2 year old toddler, I entirely agree that antibiotics should be prescribed only when evidence shows that such treatment is likely to be effective, ${ }^{1}$ and I appreciate the difficulty faced by general practitioners in explaining this to the anxious parents of distressed small children.

However, although most parents will probably accept an explanation for why antibiotics should not be prescribed, advice on alternative means of relieving the child's discomfort is essential. To send a parent away with nothing except a child still in pain can only put the doctor-patient relationship in jeopardy.

Elizabeth King senior research fellow Mental Health Group, Department of Psychiatry, University of Southampton, Royal South Hants Hospital, Southampton SO14 OY

Geak@soton.ac.ukDamoiseaux 
1 Damoiseaux RAMJ, van Balen FAM, Hoes AW, Verheij TJM, de Melker RA. Primary care based randomised, double blind trial of amoxicillin versus placebo for acute otitis media in children aged under 2 years. $B M$ 2000;320:350-4. (5 February.)

\section{Results do not justify conclusions}

EDITOR-We question the conclusions of Damoiseaux et al from the results of their randomised trial of antibiotic treatment in acute middle ear infection in young children. ${ }^{1}$ Setting to one side a certain lack of clarity about the all important randomisation procedures (how does a block size of two produce an imbalance of six between arms?), we note that the authors emphatically state several times that the benefits are "not sufficiently important clinically to prescribe antibiotics for every child."

How do they get from the data to that conclusion? Is this what they would want for their children, or is it an evidence based assessment of the decision that a representative sample of parents of children with otitis media would make? As parents, we tend to the opposite conclusion-that a day less fever, less pain and analgesic, and probably less risk of serious bacterial complications such as meningitis, ${ }^{2}$ outweigh concerns about diarrhoea and asthma as raised by Cantekin above. Following the authors' lead in ignoring financial costs, we can see that individual benefit might be outweighed by societal loss (induction of antibiotic resistance). But has this loss been measured and subjected to trade-off analysis? Surely, the authors' dogmatic conclusion is possible only after a more thorough assessment of all the salient probabilities (hospital admissions, hospital acquired infections, total dose of antibiotic used, probability of causing resistance, probabilities of infection by resistant strains, and resulting morbidity and mortality), the most important being the values people and society attach to the various outcomes.

R J Lilford professor of health services research David Braunholtz senior research fellow

D.A.Braunholtz@bham.ac.uk

Department of Public Health and Epidemiology,

University of Birmingham, Birmingham B15 2TT

1 Damoiseaux RAMJ, van Balen FAM, Hoes AW, Verheij TJM, de Melker RA. Primary care based randomised, double blind trial of amoxicillin versus placebo for acute otiti media in children aged under 2 years. BMJ 2000 320:350-4. (5 February.)

2 Rothrock SG, Harper MB, Green SM, Clark MC, Bachur R, Mcllmail DP, et al. Do oral antibiotics prevent meningitis and serious bacterial infections in children with Streptococcus pneumoniae occult bacteremia? A meta-analysis. Pediatrics 1997;99:438-44.

\section{Study raises concerns}

EDITOR-We have concerns about the article by Damoiseaux et al. ${ }^{1} \mathrm{~A}$ recent evidence based study found that $80 \%$ of cases of acute otitis media resolve without antibiotic treatment. ${ }^{2}$ Results from myringocentesis studies suggest that at least $20 \%$ of cases of acute otitis media are purely viral. ${ }^{3}$ Acute suppurative otitis media therefore seems to start with an acute secretory phase due to viral infection, which is followed by secondary colonisation with bacteria leading to the suppurative phase. This is perhaps one of the reasons why the difference between the treatment and placebo groups was not more significant in the study by Damoiseaux et al.

We question the criteria the authors used for diagnosing acute otitis media. In our institute's series injection along the handle of the malleus and annulus of the tympanic membrane is often a variation in normal appearance and frequently occurs in crying children with no ear disease at all. We were also surprised that no patients were excluded because of problems of seeing the tympanic membrane due to either wax or the extremely narrow external auditory canal and angled tympanic membrane often found in children under 2 years of age.

Finally, 27 children $(10 \%$ of the study population) were excluded because they were thought to require antibiotics by the doctor. These children probably had severe acute suppurative otitis media and had they been included in the study then the results may well have been different.

G Sandhu specialist registrar in otolaryngology H A Saleh specialist registrar in otolaryngology T Wright professor of otolaryngology

anthony.wright@ucl.ac.uk

Institute of Laryngology and Otology, Royal National Throat, Nose and Ear Hospital, London WC1X 8DA

1 Damoiseaux RAMJ, van Balen FAM, Hoes AW, Verheij TJM, de Melker RA. Primary care based randomised, doumedia in children aged under 2 years. BMJ 2000; $320 \cdot 350-4$ (5 Febriay.)

O'Neill P. Acute otitis media. BMJ 1999:319:833-5.

3 Recent advances in otitis media. Report of the sixth research conference. Ann Otol-Rhinol-Laryngol-Suppl $1998 ; 174: 1-94$

\section{Authors' reply}

Editor-We agree with Thornett that doctors find it difficult to convince worried parents that watchful waiting is acceptable treatment for their child with acute otitis media. As we said in our last sentence, analgesics could be offered, although analgesics have been given regularly in only a few studies and the optimal dose for use in acute otitis media remains unknown. ${ }^{1}$ Our results were not merely repeating evidence for lack of effectiveness since earlier evidence concerning children under 2 years of age was inconclusive. Importantly, this lack of evidence resulted in recommendations to prescribe antibiotics for acute otitis media in this age group as mentioned by Cantekin.

We do not advocate sending children home in pain, which is a concern of Thornet and King. However, prescribing antibiotics knowing that they do not reduce pain cannot be considered good clinical practice. Our study also showed that in children under 2 years old antibiotics are of limited value in resolving symptoms. We have to look for other management options for acute otitis media. Research focusing on optimal symptomatic treatment may be worth while.

Our randomisation procedure was not completely clear to Lilford and Braunholtz Ours was a multicentre trial with 53 participating general practitioners, so at certain practices not all dispensed suspensions were used by the end of the trial. Even with a two block randomisation a minor imbalance of six is possible and acceptable.
As we stated in the methods section of our paper, our aim was to assess whether a clinical relevant difference of $20 \%$ existed. We do not consider the observed, significant, difference of $13 \%$ to be clinically relevant. Parents should be told about these minor effects and that serious bacterial complications such as meningitis are unlikely to be prevented by oral antibiotics. ${ }^{2}$ Parents may then choose treatments with fewer side effects than antibiotics. The prescription of antibiotics for this common childhood disease is certainly influenced by the values individuals and society attach to the various outcomes. Most importantly, this requires adequate information of parents to facilitate a decision.

The concerns of Sandhu et al have to be seen in the right perspective. Our study was performed in a primary care population. Otolaryngologists in the Netherlands see less than $5 \%$ of children with acute otitis media, usually after they have been referred by a general practitioner. These are most probably the most serious cases. Obviously, our conclusion does not apply to these children. Our diagnosis agreed with the guidelines on acute otitis media of the Dutch College of General Practitioners. In two previous studies concordance in diagnosis between general practitioners and otolaryngologists was excellent. ${ }^{34}$ If no eardrum was seen-for example, owing to wax-the child was not considered for this study and did not have to be registered since diagnosis based on symptoms alone is not very specific. Our conclusion that most children with acute otitis media seen in primary care can be managed by watchful waiting, even those under 2 years old, does not imply that nobody should get antibiotics. But these children cannot yet be identified at the first visit. Good clinical judgment and proper follow up will always be needed in each case.

R A M J Damoiseaux general practitioner F A M van Balen general practitioner A W Hoes professor of clinical epidemiology T J M Verheij professor of general practice $\mathbf{R}$ A de Melker professor of general practice Department of General Practice and Julius Centre for General Practice and Patient Oriented Research, University Medical Centre Utrecht, Universiteitsweig 100, 3584 CG Utrecht, Netherlands

1 Bertin L, Pons G, d'Athis P, et al. A randomised, double blind, multicentre controlled trial of ibuprofen versus acetaminophen and placebo for symptoms of acute otits media in children. Fundam Clin Pharmacol 1996;10:378-92. 2 Rothrock SG, Harper MB, Green SM, Clark MC, Bachur Rothrock SG, Harper MB, Green SM, Clark MC, Bachur Mcllmail DP, et al. Do oral antibiotics prevent meningit and serious bacterial infections in children with StreptoPediatrics 1997:99:438-44.

3 Van Buchem FL, Dunk JHM, van't Hof MA. Therapy of acute otitis media: myringotomy, antibiotics, or neither? double blind study in children. Lancet 1981;ii:883-7.

4 Appelman CLM, Claessen JWPJ, Touw-Otten FWMM, Hordijk GJ, de Melker RA. Co-amoxiclav in recurrent acute otitis media: placebo controlled study. BMJ 1991;315:98-102

\section{UK case of congenital rubella can be linked to Greek cases}

EDITOR-Giannakos et al reported on four infants with congenital rubella syndrome born in Greece after an outbreak of rubella 
that peaked in January 1999. ${ }^{1}$ We report a case of congenital rubella in Scotland late in 1999 that can also be linked to this outbreak.

At least four universities in the United Kingdom (three in England and one in Scotland) reported outbreaks of rubella early in 1999, all of which included students from Greece. ${ }^{2}$ In Grampian, Scotland, 39 reported cases were confirmed by laboratory testing, and two Greek students were among the first five patients. ${ }^{3}$ The only infant reported with congenital rubella for 1999 was born in the Grampian Health Board area in December. ${ }^{4} \mathrm{He}$ was admitted to hospital in Aberdeen at the age of 3 months with a purpuric rash and failure to thrive and was found to be positive for rubella IgM. The baby's mother had been immunised as a schoolgirl, had rubella antibodies detected in pregnancy in 1996, and had no symptoms or known contact with rubella early in this pregnancy. However, reinfection in pregnancy was retrospectively confirmed by tests on stored antenatal blood. The baby is developmentally delayed and has intracranial calcification but no detectable eye or cardiac abnormalities. He also has severe gastrointestinal reflux, which resulted in aspiration pneumonia.

Since 1990, 46 live births and two stillbirths have been reported to the national congenital rubella surveillance programme in the UK. Twelve of these occurred in 1996 after a resurgence of rubella infection that mainly affected young men. ${ }^{5}$ No cases were reported in 1997 or 1998. The dramatic reduction in cases of congenital rubella and terminations associated with rubella in the UK in the past 20 years has been achieved by maintaining a high rate of immunisation uptake. Indeed, in the Grampian area the uptake of the measles-mumps-rubella vaccine (MMR) in 2 year old children is currently $91 \%$. MMR uptake in the UK as a whole in 2 year old children, however, has declined since 1995 to $87.8 \%$ (range $63.6 \%$ to $100 \%$ ) at the end of 1999 , a level that is insufficient to prevent renewed circulation of rubella infection in the long term.

Although women who travel abroad during early pregnancy or have recently arrived here from countries with less successful or disrupted vaccination programmes-for example, eastern Europe-are likely to be at higher risk, this case shows that you don't have to travel to find rubella.

Pat Tookey coordinator

National Congenital Rubella Surveillance

Programme, Department of Epidemiology and

Biostatistics, Institute of Child Health, London

WC1N 1EH

p.tookey@ich.ucl.ac.uk

Pamela Molyneaux consultant virologist

Department of Medical Microbiology, Aberdeen Royal Infirmary, Aberdeen AB25 2ZN

Peter Helms professor of child health

Department of Child Health, University of

Aberdeen, Aberdeen AB25 2ZD

Competing interests: None declared.

1 Giannakos G, Pirounaki M, Hadjichristodoulou C. Incidence of congenital rubella in Greece has decreased. BMJ 2000;320:1408. (20 May.)
2 Rubella in university students. Commun Dis Rep CDR Wkly 1999;9:113:116

3 Rubella in Grampian Health Board. SCIEH Weekly Repor 1999;33:77.

4 Molyneaux P. Congenital rubella infection following documented maternal reinfection. SCIEH Weekly Repor 2000;34:85.

5 Tookey PA, Peckham CS. Surveillance of congenita rubella in Great Britain, 1971-96. BMJ 1999;318:769-70.

\section{Compulsory retirement of experts}

EDITOR-Sackett, in his article on the compulsory retirement of experts, suggests that experts are helpless to affect the victimisation that they may experience in their expert role. ${ }^{1}$ He speaks of the "sins" of experts as if they are immutable once present. The consequence of his answer, for the expert to withdraw from the conversation, is the loss of the expert's continued thought on the subject.

I suggest redefining an expert as someone who has spent more time and energy studying a particular field than others, can see more deeply into the field, and can, therefore, deepen the conversation for others. Experts who choose to facilitate inquiry, rather than regurgitate their expertise, can be the most valued educators in our world. The questions that propelled them towards expertise can now become the questions that enable others to share in the discovery process.

Parker Palmer, in his book The Courage to Teach, recommends a "community of truth" approach to create a partnership between expert teachers and learners on the basis of a shared vision for a desire to continue to find new answers collectively. ${ }^{2}$ Teachers thus facilitate new conversations and then engage in these conversations as learners themselves. This approach recognises that learning is life long and that teachers are active participants in the quest for knowledge. To participate in this manner, teachers must be willing to experience their vulnerability as learners themselves in the presence of those whom they teach and guide. Teachers of this kind must do the process work necessary to enable them to invite their learners, or their junior colleagues, to hurt their feelings as well as earning their disapproval, as discussed by Sackett. I therefore do not second the call for the compulsory retirement of experts but call for the compulsory shift in attitude of experts so that they can continue to participate in the conversations that will move our disciplines forward more fully and expeditiously.

Hershey S Bell director, faculty development Department of Community and Family Medicine, Duke University Medical Center, DUMC 3886 , Durham, North Carolina 27710, USA

1 Sackett DL. The sins of expertness and a proposal for redemption. BMJ 2000;320:1283. (6 May.)

2 Palmer PJ. The courage to teach. San Francisco: Jossey-Bass, 1998.

\section{Public health must make best use of leadership resources}

EDITOR-In a letter commenting on the white paper Saving Lives: Our Healthier
Nation ${ }^{1}$ McPherson pondered, "Surely the debate... must now be ... how can we enable the best people to enter the profession without glass ceilings and other unnecessary barriers to career development?"2 The tide of modernisation seems to be running with McPherson rather than with Taylor and Saunders, who believe that doctors should lead public health teams. ${ }^{3}$

There is no reason why the prime minister's challenge to the professions-to break down barriers between professions-should not apply to public health, which more than many parts of the NHS needs effective leadership. This should be provided by the person with the most appropriate skills, experience, and personal characteristics. The possession of a medical degree does not necessarily or automatically confer these benefits, although it undoubtedly is an important part (although not an exclusive one) of the professional toolkit.

The type of special pleading that suggests that only one professional group can lead is rapidly disappearing from many parts of the NHS, and rightly so. If public health wants a better profile than the one it often currently seems to have it should make best use of whatever leadership resources it has, rather than fight internal battles about who is in charge.

Nigel Edwards director of policy

NHS Confederation, London SW1P 4ND

nigel.edwards@confed.co.uk

1 Department of Health. Saving lives: our healthier nation. London: Stationery Office, 1999 .

2 McPherson K. Removing barriers to career development in public health. BMJ 2000;320:448. (12 February.)

3 Taylor S, Saunders C. Career development in public health. BMJ 2000;321:112-3. (8 July.)

\section{Doctors must be more aware of problems of gay, lesbian, and bisexual youth}

EDITOR-In their editorial on suicidal behaviour in gay, lesbian, and bisexual youth Bagley and D'Augelli refer to the effects of societal and institutional homophobia on the mental health of these young people. ${ }^{1}$ We agree that restrictive legislation allows intolerance in the community and its institutions to rest unchallenged.

The medical profession, as an important social institution, has a role in working against prejudice. It also has a duty to do so, at least partly to atone for its treatment of gay, lesbian, and bisexual people in the past. Almost all people seek medical advice at some time. One way or another, the success of many clinical interventions is partly determined by a trusting relationship between doctor and patient.

Several studies have shown that lesbians and gay men still have adverse experiences when consulting health professionals, especially mental health professionals. ${ }^{23}$ Such experiences include the health professional ignoring the effects of living as a stigmatised person, ascribing problems to the person's sexuality, focusing on sexuality when it is not 
the issue, and failing to acknowledge the importance of the person's partner.

Legislative change is critical as part of a broader social process leading towards acceptance of all minority groups in our society. New Zealand's human rights legislation has helped reduce prejudice by making exclusionary employment, educational, housing, and other policies and practices illegal. As a profession, however, we still have much to do. In a study that we were involved in many of the lesbians concerned considered that ignorance was the cause of problems that they had had with clinicians ${ }^{3}-\mathrm{a}$ view supported by other researchers. ${ }^{4}$

Our undergraduate and postgraduate training needs to include material on different sexual orientations and the relevant developmental and life issues. We are not especially good at this in New Zealand, despite our legislation. In the United Kingdom the profession should take a lead by tackling these issues to show that at least some sectors of the wider community are ready for change.

S C D Collings visiting fellow

Department of Psychiatry and Behavioural Sciences, Royal Free and University College Hospital Medical School, University College, London NW3 2PF

sunnyc@wnmeds.ac.nz

Sarah Welch registrar

Auckland Hospital, Auckland, New Zealand

Bagley C, D'Augelli AR. Suicidal behaviour in gay, lesbian, and bisexual youth. BMJ 2000;320:1617-8. (17 June.)

2 McFarlane E. Diagnosis homophobic-the experiences of lesbians, gay men and bisexuals in mental health services. London: Project for Advocacy, Counselling and Education, 1997.

3 Welch S, Collings S, Howden-Chapman P. Lesbians in New Zealand: their mental health and satisfaction with mental health services. Aust NZ J Psychiatry 2000;34:256-63.

4 Lapsley H. Mental health issues for lesbians. In: Romans S, ed. Folding back the shadows: a perspective on women's mental health. Dunedin: University of Otago Press, 1998:137-46.

\section{Lifestyle modification may be beneficial in diabetes care}

EDITOR-I am moved to write to you for the first time in over 20 years as a BMA member in response to the editorial by Byrne and Wild on diabetes care. ${ }^{1}$ This includes the statement that the benefits of controlling weight, stopping smoking, increasing physical activity, and eating a Mediterranean diet have not been shown for people with diabetes. Hence we should treat them instead with a large range of pharmaceutical agents. I waited for a furore to erupt in the letters pages but have found nothing. I wish to protest along two main lines.

Firstly, the assumption is that if there is no published evidence the benefit therefore does not exist. This is false both in general and specifically in this case. Trials show considerable bias in the areas they investigate, reflecting the interests of the (prescribing) doctor. As they are often funded by pharmaceutical companies they overrepresent trials of the products manufactured by these companies-specifically, the current increase in the incidence of diabetes closely parallels an increase in obesity and decrease in activity. Common sense says that if these trends are reversed the likelihood of diabetes and all its problems abates. The appeal to evidence, laudable in itself, must not focus too narrowly on facts or, for that matter, only on published ones. Has anyone proved by a randomised controlled trial that appendicectomy is beneficial in appendicitis?

Secondly, and possibly more importantly, we have the problem of ownership. There is still a strong trend for caring but paternalistic doctors to do what they can do, which usually entails writing a prescription rather than emphasising the responsibilities of patients to concern themselves with factors that they can, with help, control.

Lifestyle modification as a way of achieving benefit for patients remains a Cinderella, especially in secondary care. Perhaps a trial of obese, inactive, smoking patients with diabetes, who are taking angiotensin converting enzyme inhibitors, aspirin, statins, and so on, compared with those who lose weight, gain fitness, and escape from nicotine addiction would be worth while, to test what common sense suggests. I doubt whether there would be many surprises.

S J Redmond general practitioner Lewisham Medical Centre, Liverpool L11 1DL

1 Byrne C, Wild SH. Diabetes care needs evidence based interventions to reduce risk of vascular disease. $B M$ J 2000:320:1554-5. (10 June.)

\section{Do you admit to working within the system?}

\section{Culture of not telling tales has to end}

EDITOR-Richard wonders if he should admit to being a doctor when the casualty officer misses his daughter's fracture and even after seeing the $x$ ray film, gets the diagnosis and treatment wrong. ${ }^{1}$ There is no dilemma. The casualty officer is a poorly performing doctor. He is not only lacking in knowledge but, seemingly, unaware of his own ignorance.

Do his seniors know this? What help does he need to become a better doctor? Does the department provide proper training for its senior house officers? Do they have guidelines for use of radiography?

If the NHS is ever to be a first class service we need to learn to use such incidents constructively. The accident and emergency consultant needs to be told and to take action. There seem to be issues concerning this senior house officer's attitude and competence, and possibly wider problems of staff training and supervision.

The culture of not telling tales has to end, otherwise the NHS will continue to fail patients like Richard's daughter, the Bristol babies, and thousands more.

Patrick Bower clinical governance lead

Balham, Tooting and Wandsworth Primary Care Group, London SW18 4EA

PJBOWER@aol.com

Richard B. A doctor's dilemma: Do you admit to workin within the system? BMJ 2000;320:1596. (10 June.)
If we see errors being made how can we be expected to stay silent?

EDITOR-Should a doctor declare "insider" status when family become patients?' I offer three recent instances to argue my case.

My son left the accident and emergency department with a diagnosis of soft tissue injury to his right hand. Later I learnt that he had punched something harder than he had bargained for, and I looked for the missing fourth knuckle; this adds up to a fracture of the metacarpal neck. We needed advice before his next rowing event. At my request to have the $x$ ray film checked the accident and emergency triage nurse invited me to make a formal complaint. Instead I found the duty orthopaedic registrar, who reviewed the case. The fracture was confirmed and practical advice received from the young doctor, also an oarsman.

Not long after, my son could not walk because of severe pain in his ankle after slipping on the towpath. A decision not to send him for radiography was made as a teaching point to a medical student while I as father dumbly acquiesced. The school matron was unimpressed with my performance and took him back for radiography, which showed a fractured fibula.

I was next in accident and emergency with my octogenarian aunt who had fractured her hip. Later I was at her bedside as she struggled with hypoxaemia and confusion. The senior house officer wanted to treat supposed atrial fibrillation. After 20 years as a heart surgeon and four hours watching my aunt's electrocardiogram I knew she was in sinus rhythm. But she was deteriorating. I was concerned that she might arrest and we had no plan. Should she be ventilated? This was a reasonable question to share with her nearest and dearest relative, but it took a little perseverance on my part to get beyond the bland reassurances that I should leave the management to them. Together we got her through the night, and, with her fracture skilfully fixed, she is restored to her full and happy life.

If we see errors being made that might threaten relatives' and friends' wellbeing, how can we be expected to stay silent? When I am in my more frequent and more comfortable role as the doctor I always invite my patients to involve their family, medically or otherwise, as fully as they wish. It keeps them "on side," it might reduce errors, but it simply feels like the right thing to do.

Tom Treasure professor of cardiothoracic surgery University of London, St George's Hospital, London SW17 0QT

tom.treasure@ukgateway.net

1 Richard B. A doctor's dilemma: Do you admit to working within the system? BMJ 2000;320:1596. (10 June.)

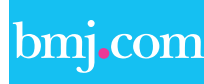

Rapid responses

Correspondence submitted electronically

is available on our website 